\section{Science in crisis}

Last October the Economist, a weekly magazine of news and analysis produced in London, published a prominent (the front cover, the editorial and a long article entitled "Unreliable research: Trouble at the lab") and devastating attack on science. ${ }^{1}$ The salient point was the irreproducibility of many reported results, especially in the biomedical sciences. Although pharmaceutical companies have been criticized for manipulating clinical trials, ${ }^{2}$ recent attempts by company researchers to reproduce published academic research have found that most results cannot be repeated $[2,3]$.

Some of the more obvious possible reasons for this state of affairs were discussed. One is the general bias towards positive results. ${ }^{3}$ Many journals are, indeed, reluctant to publish negative results. It seems to follow that positive results are submitted for publication with little self-criticism by the authors. Journals are also reluctant to publish comparisons of results obtained from the same experiments carried out by different laboratories; such comparisons are perceived as being rather uninteresting. The reluctance to publish negative results appears to be driven by the thirst for popularity. This is especially prominent with commercial journals like Nature, which derive their income not only from subscribers (among which libraries probably constitute a small minority) but also from the many advertisements that fill their pages. Their income is, therefore, directly related to circulation number and their editorial policies are clearly aimed at maximizing that number. Nowadays there exists a very large number of commercial journals and even those published by learned societies are, especially in the case of large societies like the American Chemical Society or the American Physical Society, which publish many journals, often managed by quasi-autonomous publishing divisions that in many ways act like commercial publishers; they doubtless contribute valuable income to the parent society and seek to maximize circulation number.

Another reason is the sheer volume of papers. Regular journals send submitted papers out for review (the more commercial journals may reject prima facie without review those judged unlikely to be popular), the reviewers typically being scientists who are themselves writing papers. It is no wonder that both the papers and the reviews are undertaken increasingly hastily and carelessly. One obvious sign of that is a growing number of trivial errors - even proofreading tends to be careless nowadays.

A deeper reason for the unreliability lies with statistical mistakes. A great deal of research nowadays is dependent upon statistics. They can be useful, but only if properly applied, and how to do that is probably beyond the ken of most of the scientists who rely upon them. As a result of deficiencies such as inadequate statistical power, Ioannides concluded that "most published research findings are probably false" [5]. Errors in the statistics are to a large degree generic and should, therefore, be readily picked up in the reviewing process. The Economist article made much of the inadequacies of peer review, but with a rather inconclusive outcome. The reality is that most scientists are flooded with requests to review papers. I myself have always argued that one should review roughly as many papers as one submits for publication. But, nowadays, many of the papers that journals send out for review-and the editors, especially the honorary editors of learned society journals who are active research scientists, are themselves overwhelmed - are so trivial or so ignorant of the fundamental principles of scientific research that it is hardly worth spending very much time on them. To reiterate: what is lacking is self-review prior to submission. But the very plethora of journals encourages the publication of triviality, and this trend has been immeasurably amplified by the of appearance of "open access", internet journals where publication can be secured by the payment of a fee, in a manner akin to vanity publishing in the literary world. Many of the "open access" journals pay lip service to peer review, but the psychological impact of the knowledge that the paper only exists in electronic form and can, therefore, be corrected at any time, seems to encourage extreme superficiality in the reviewing process.

The Economist also touched on the growing number of fraudulent, in one way or another, publications. Practically every issue of Laborjournal, a monthly magazine focusing on the life sciences, published in Germany, contains an account of one or more papers found to be fraudulent. The pressure that has engendered this alarming trend is the same as that driving the ever increasing number of publications - careerism. The Economist quotes Brian Nosek, a psychologist at the University of Virginia: "There is no cost to getting things wrong, the cost is not getting them published."

\footnotetext{
1 Issue dated 19 October 2013.

2 See, e.g., [1]

3 See the comments by Kelly on this bias in nanotechnology [4].
} 
This is not the first time that warnings about the way science is going have been raised. A notable example is Herbert Dingle's book, Science at the Crossroads [6]. The issue at stake was falling into the error "of imagining how nature ought to behave and then assuming that she does so, instead of examining nature with an open mind and then expressing her observed behaviour in rational terms." Dingle's book summarizes a debate that was, in part, carried out in the columns of The Times and the Listener and which was, therefore, just as public as the present airing in the Economist. Nevertheless, the latter seems to be fundamentally different in spirit. The present debate is really about the integrity of scientists. The malaise is that "most research investment today goes not into science but into elaborate market research and promotional activities" [7]. Ernst also points out that "the most important virtue or value in science is honesty and self-criticism." Similar statements have been made by R.P. Feynman [8]. Adherence to these high standards would eliminate the problems highlighted in the Economist.

Nevertheless, that statement belies the very different environment in which scientists operate today, compared with the era of Dingle and Feynman. Firstly, many, if not most, scientists work in universities, and universities have become very different places in this postmodern era [9]. Secondly, most scientists now obtain funding for their research from government research agencies. These agencies have become increasingly prescriptive about the research they fund. Ernst [7] criticizes this development with the following words "the basic idea or fear behind these governmental initiatives is that scientists are still overwhelmingly individualists who have to be told how to make themselves useful to society." This prescriptiveness has, generally, had a disastrous effect both on the creative productivity of science and the enjoyment inherent in doing it. In 2012, a movement called "Science for the Future" was launched in London to roundly criticize the Engineering and Physical Sciences Research Council for its intolerable prescriptiveness (Figure 1). Thirdly, the number of scientists has increased unimaginably (the Economist estimates 6-7 million researchers worldwide): science has practically become a mass activity.

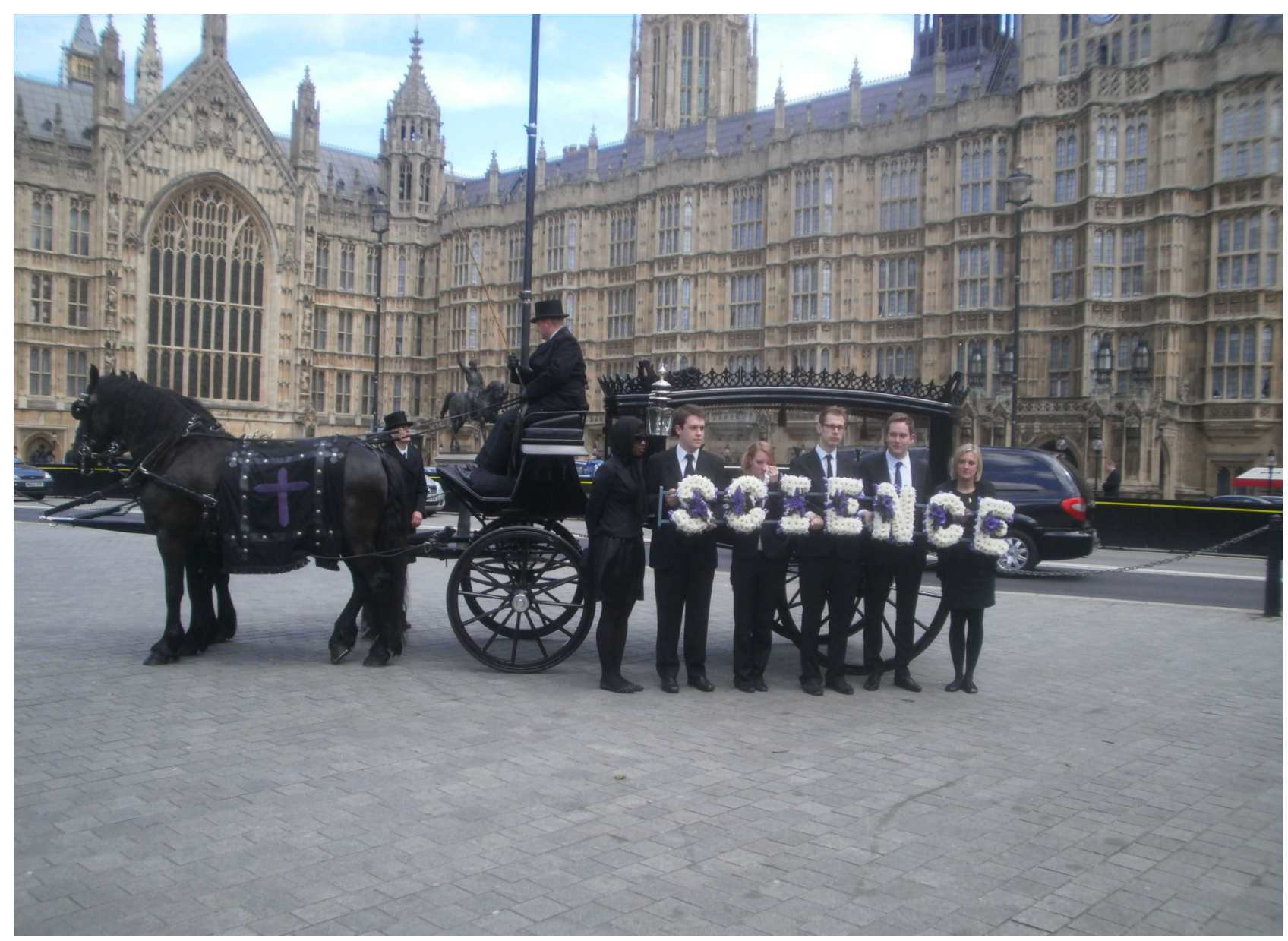

Figure 1. A hearse bearing a coffin containing SCIENCE outside the Houses of Parliament in London, before setting off for 10 Downing St in order to deliver a petition to the Prime Minister. The event was organized by Science for the Future on 15 May 2012. 
I do not mention these three facts in order to suggest that scientists might be excused because of an increasingly hostile environment inimical to honesty and self-criticism. ${ }^{4}$ Rather, it is to point out that these contemporary features are inimical to good science and that much greater effort needs to be put into defending traditional values. For a variety of reasons, perhaps the most common being that it was simply easier to make at first small, then larger compromises with those values in order to ensure a constant flow of funds into one's laboratory, than to robustly object to the erosion of those values, this effort has been inconspicuous among the majority. Does this mean that "real" science will continue to be done in isolated bubbles only while the rest becomes indistinguishable from mass entertainment? Can the "bubbles" then survive in the midst of so much "noise"?

J.J. RAMSDEN

\section{References}

1. D. Healy. Brand "fascism" and academic stalking. J. Biol. Phys. Chem. 12 (2012) 71-84.

2. F. Prinz, T. Schlange and K. Asadullah. Believe it or not: how much can we rely on published data on potential drug targets? Nature Reviews Drug Discovery 10 (2011) 712-713.

3. C.G. Begley and L.M. Ellis. Raise standards for preclinical cancer research. Nature 483 (2012) 531-533.

4. M.J. Kelly. Nanotechnology and manufacturability. Nanotechnol. Perceptions 7 (2011) 79-81.

5. J.P.A Ioannidis. Why most published research findings are false. PLoS Medicine 2(2005) e124.

6. H. Dingle. Science at the Crossroads. London: Martin Brian \& O'Keeffe (1972).

7. R. Ernst. The responsibility of science and scientists. In: Transdisciplinarity: Joint Problem-Solving among Science, Technology and Society (eds J. Thompson Klein, W. Grossenbacher-Mansuy, R. Häberli, A. Bill, R.W. Scholz \& M. Welti), pp. 81-93. Basel: Birkhäuser (2001).

8. R.P. Feynman. Cargo cult science. Engineering and Science 37 (June 1974) 10-13.

9. F. Webster. The postmodern university, research and media studies. J. Biol. Phys. Chem. 13 (2013) 96-104.

4 The connexions are not necessarily obvious. (1) The postmodern university prioritizes bringing in research income rather than upholding the truth. (2) In order to successfully receive funds from the government research agencies, a strong measure of self-promotion and exaggeration of the impacts of the proposed research is generally needed. (3) Science begins to acquire some of the features of mass culture (mass entertainment), such as a preference for showing rather than exploring. 